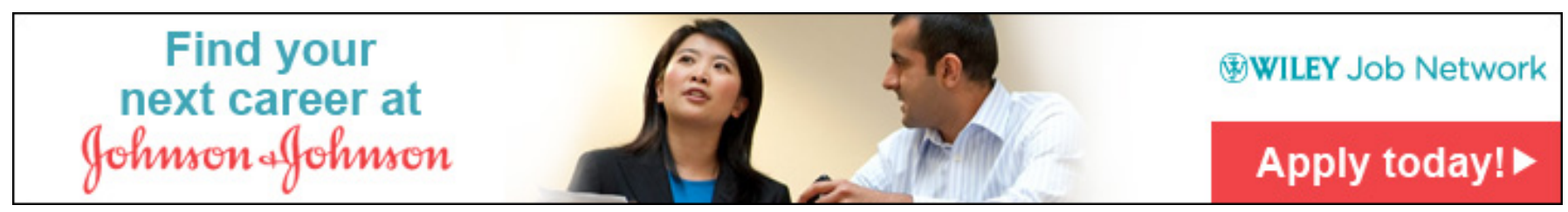

You have full text access to this content

\title{
EVIDENCE ON FEATURES OF A DSGE BUSINESS CYCLE MODEL FROM BAYESIAN MODEL AVERAGING
}

1. Rodney W. Strachan,

2. Herman K. Van Dijk ${ }^{\ddagger}$

Article first published online: 23 JAN 2013

DOI: 10.1111/j.1468-2354.2012.00737.x

(C) (2013) by the Economics Department of the University of Pennsylvania and the Osaka University Institute of Social and Economic Research Association

Issue

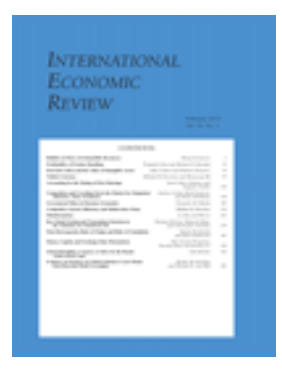

\section{International Economic Review}

Volume 54, Issue 1, (/doi/10.1111/iere.2013.54.issue-1/issuetoc) pages 385-402, February 2013

Additional Information

\section{How to Cite}

Strachan, R. W. and Van Dijk, H. K. (2013), EVIDENCE ON FEATURES OF A DSGE BUSINESS CYCLE MODEL FROM BAYESIAN MODEL AVERAGING. International Economic Review, 54: 385-402. doi: 10.1111/j.1468-2354.2012.00737.x

\section{Author Information}

The Australian National University, Australia; Erasmus University Rotterdam and VU University, Amsterdam, The Netherlands 
‡ We would like to thank Frank Schorfheide and three anonymous referees for extensive comments that led to a substantial revision and extension of the results presented in the original working paper. A preliminary version of this article was presented at the U.S. Federal Reserve Bank in 2008 and at Cambridge University in 2011. We also thank Luc Bauwens, Geert Dhaene, John Geweke, David Hendry, Lennart Hoogerheide, Soren Johansen, Helmut Lutkepohl, Christopher Sims, Mattias Villani, and Anders Warne for helpful discussions on the topic of this article. Of course, any remaining errors remain the responsibility of the authors. Van Dijk acknowledges financial support from the Netherlands Organization of Scientific Research. Please address correspondence to: Rodney W. Strachan, Research School of Economics, The Australian National University, HW Arndt Building 25a, Canberra 0200, Australia. Phone: +61 26125 3363. Fax: +61 26125 5124. E-mail: rodney.strachan@anu.edu.au (mailto:rodney.strachan@anu.edu.au)

† Manuscript received May 2009; revised February 2012.

‡ We would like to thank Frank Schorfheide and three anonymous referees for extensive comments that led to a substantial revision and extension of the results presented in the original working paper. A preliminary version of this article was presented at the U.S. Federal Reserve Bank in 2008 and at Cambridge University in 2011. We also thank Luc Bauwens, Geert Dhaene, John Geweke, David Hendry, Lennart Hoogerheide, Soren Johansen, Helmut Lutkepohl, Christopher Sims, Mattias Villani, and Anders Warne for helpful discussions on the topic of this article. Of course, any remaining errors remain the responsibility of the authors. Van Dijk acknowledges financial support from the Netherlands Organization of Scientific Research. Please address correspondence to: Rodney W. Strachan, Research School of Economics, The Australian National University, HW Arndt Building 25a, Canberra 0200, Australia. Phone: +61 26125 3363. Fax: +61 26125 5124. E-mail: rodney.strachan@anu.edu.au (mailto:rodney.strachan@anu.edu.au)

\section{Publication History}

1. Issue published online: 23 JAN 2013

2. Article first published online: 23 JAN 2013

- Abstract

- Article (/doi/10.1111/j.1468-2354.2012.00737.x/full)

- References (/doi/10.1111/j.1468-2354.2012.00737.x/references)

- Cited By (/doi/10.1111/j.1468-2354.2012.00737.x/citedby)

View Full Article (HTML) (/doi/10.1111/j.1468-2354.2012.00737.x/full) Get PDF (746K) (/doi/10.1111 /j.1468-2354.2012.00737.x/pdf)

The empirical support for features of a Dynamic Stochastic General Equilibrium model with two technology shocks is evaluated using Bayesian model averaging over vector autoregressions. The model features include equilibria, restrictions on long-run responses, a structural break of unknown date, and a range of lags and deterministic processes. We find support for a number of features implied by the economic model, and the evidence suggests a break in the entire model structure around 1984, after which technology shocks appear to account for all stochastic trends. Business cycle volatility seems more due to investment-specific technology shocks than neutral technology shocks.

View Full Article (HTML) (/doi/10.1111/j.1468-2354.2012.00737.x/full) Get PDF (746K) (/doi/10.1111 /j.1468-2354.2012.00737.x/pdf) 


\section{More content like this}

Find more content:

- like this article (/advanced/search/results?articleDoi=10.1111/j.1468-2354.2012.00737.x\& scope $=$ allContent $\&$ start $=1 \&$ resultsPerPage $=20$ )

Find more content written by:

- Rodney W. Strachan (/advanced/search/results?searchRowCriteria[0].queryString="Rodney W. Strachan"\&searchRowCriteria[0].fieldName=author\&start=1\&resultsPerPage=20)

- Herman K. Van Dijk (/advanced/search/results?searchRowCriteria[0].queryString="Herman K. Van Dijk"\&searchRowCriteria[0].fieldName=author\&start=1\&resultsPerPage=20)

- All Authors (/advanced/search/results?searchRowCriteria[0].queryString="Rodney W. Strachan" "Herman K. Van Dijk"\&searchRowCriteria[0].fieldName=author\&start=1\&resultsPerPage=20) 